\title{
What do Dosimetric Errors Encountered in Prostate Implant Brachytherapy tell us about $\alpha / \beta$ ?
}

\author{
Paul Mobit ${ }^{1,3}$, Ephraim Agyingi ${ }^{2}$, Satyaseelan Packianathan ${ }^{1}$ and Claus Chunli Yang ${ }^{1}$ \\ ${ }^{1}$ Department of Radiation Oncology, University of Mississippi Medical Center, 350 West Woodrow Wilson Dr, Jackson, MS 39213, USA \\ ${ }^{2}$ School of Mathematical Sciences, Rochester Institute of Technology, Rochester, NY 14623, USA \\ ${ }^{3}$ Cameroon Oncology Center, P O Box 1870, Douala, Cameroon
}

*Corresponding author: Paul Mobit, Department of Radiation Oncology, University of Mississippi Medical Center, 350 West Woodrow Wilson Dr, Jackson, MS 39213, USA, Tel: 001601815 6930; E-mail: mobit_paul@yahoo.ca

Received date: Jan 06, 2015, Accepted date: Feb 13, 2015, Publication date: Feb 17, 2015

Copyright: $\odot 2015$ Mobit $P$, et al. This is an open-access article distributed under the terms of the Creative Commons Attribution License, which permits unrestricted use, distribution, and reproduction in any medium, provided the original author and source are credited.

\begin{abstract}
Objective: To determine the $\alpha / \beta$ ratio of prostate cancer using the linear quadratic model taking into account different radiation prescription doses and RBE for low energy gamma rays.

Methods and material: The linear quadratic model was used to evaluate the $\alpha / \beta$ ratio for prostate cancer taking into account the dosimetric errors resulting from seed displacements in prostate permanent implant brachytherapy with ${ }^{125} \mathrm{I}$ and ${ }^{103} \mathrm{Pd}$. The study assessed the variability of the $\alpha / \beta$ ratio with different prescribed external beam radiation therapy doses and published values of the relative biological effectiveness (RBE) for both ${ }^{125}$ I and ${ }^{103} \mathrm{Pd}$. The biological effective dose (BED) for prostate implant brachytherapy was equated to the external beam radiation therapy dose to derive an equation for $\alpha / \beta$ ratio.
\end{abstract}

Results: The results showed that the $\alpha / \beta$ ratio for prostate cancer varied between 1 and 4.5 for an RBE of 1.0 when an external beam dose of $78.0 \mathrm{~Gy}$ was prescribed. When published values of RBEs were incorporated into the analysis, the $\alpha / \beta$ ratio varied between 0.37 and 4.4 . The $\alpha / \beta$ ratio changed by $30 \%$ when the external beam radiation dose was increased from 72 Gy to 80 Gy.

Conclusions: Assuming an average reduction in implanted seeds brachytherapy dose between 10-20\% using ${ }^{125} \mathrm{I}$ or ${ }^{103} \mathrm{Pd}$, the realistic value of the $\alpha / \beta$ ratio for prostate tumors likely lies between 0.7 and 2.0 .

Keywords: $\alpha / \beta$ ratio; Prostate cancer; RBE; BED; Brachytherapy

\section{Introduction}

Prostate cancer is the most common cancer in American men and according to the American Cancer Society estimates that there are about 220,800 new cases per year resulting in about 27,540 deaths a year. About 1 man in 7 will be diagnosed with prostate cancer during his lifetime. Prostate cancer occurs mainly in older men but it is the second leading cause of cancer death in American men, behind only lung cancer. Treatment options for prostate cancer include radical prostatectomy, external beam radiation therapy, watchful waiting or interstitial prostate implant brachytherapy either as monotherapy or combined with external beam radiation treatment.

Interstitial brachytherapy techniques involve the implantation of radioactive sources, usually in the form of needles, seeds, or wires, directly into the tumor and surrounding normal tissues. This technique is employed for treating prostate cancers, sarcomas, breast, some brain cancers, and advanced cervical cancers. The placement of the radioactive sources for treatment can be permanent as in prostate seed implant brachytherapy or temporary as in the treatment of vaginal or cervical cancers.

Prostate seed implant (PSI) brachytherapy [1,2] can be administered as monotherapy for early stage prostate cancer or combined with external beam radiation therapy for more advanced cancers. According to the guidelines promulgated by the American Brachytherapy Society [2], the general selection criteria for PSI brachytherapy should include a life expectancy greater than 5 years and clinical stage T1b-T2c including some selected stage T3 cancers. The gleason score should be from 2 to 10 and serum PSA level should be less than $50 \mathrm{ng} / \mathrm{mL}$. There should also be no pathologic evidence of pelvic lymph node involvement and no evidence of distant metastases. PSI brachytherapy is an excellent alternative for patients who for one reason or the other are unable to present themselves daily for the 36-44 conventional fractions of external beam radiation therapy.

One of the main problems in PSI brachytherapy is that the implanted radioactive seeds are almost always somewhat displaced from their intended or planned positions $[3,4]$. The displacement is due to seed migration, compression of the target volume as the needle is inserted, and deviations in the path of the needle due to the diverting effect of the beveled tip. Yu et al. [3] noted that the average displacement was about $2 \mathrm{~mm}$ with a standard deviation of about 5 $\mathrm{mm}$. Nath et al. [4] have also shown that needle divergence in PSI can lead to a dose reduction in the prescribed target dose of anywhere between $5 \%$ and $20 \%$ when ${ }^{125}$ I seeds are used. Other dosimetric errors encountered in PSI brachytherapy arise from the effects of edema which can lead to a reduction in target dose of up to $5 \%$ and $12 \%$ for ${ }^{125} \mathrm{I}$ and ${ }^{103} \mathrm{Pd}$, respectively $[3,5]$. There are also density differences between prostate tissue and water which could also lead to a dose 
Citation: Mobit P, Agyingi E, Packianathan S, Yang CC (2015) What do Dosimetric Errors Encountered in Prostate Implant Brachytherapy tell us about $\alpha / \beta$ ?. J Nucl Med Radiat Ther 6: 214. doi:10.4172/2155-9619.1000214

Page 2 of 6

reduction of about $5 \%$. Imaging studies and inter observer differences also have a significant impact on the quality and coverage of prostate volume with the prescription isodose line [6,7].

It is therefore not unrealistic that not all the prostate volume may receive the prescribed dose as discussed above. To counter this dose reduction, the acceptance criteria for most prostate seed implant radiation treatment plans is that $\mathrm{D}_{90}$ (dose covering $90 \%$ of the prostate volume) be greater than $100 \%$ of the prescription dose [8]. Some radiation oncologists have the planning objective of $\mathrm{D}_{90}$ to be as high as $130 \%$ of the prescription dose. This means that for a prostate seeds implant administered with ${ }^{125} \mathrm{I}, 90 \%$ of the prostate volume is anticipated to receive between 160 Gy and 190 Gy even though the prescription dose is only $145 \mathrm{~Gy}$. Post implant dosimetry suggests that the $D_{90}$ ranges anywhere from $80 \%$ to over $130 \%$ of the prescription dose. So prostate seed implant brachytherapy patients tend to receive a range of dose depending on their particular circumstances and the implantation skills of the treating physicians. All these differences must be accounted for all $\alpha / \beta$ ratio calculations for PSI treatment. Usually in the calculation of the $\alpha / \beta$ ratio involving PSI, it is always assumed that the patient received the prescribed dose which is not true as explained above. The uncertainty in the implanted dose must be incorporated into the calculation of the $\alpha / \beta$ ratio.

It has also become clear over time that traditional external beam radiation doses alone ranging from 66-70 Gy may not achieve an acceptably high degree of local disease control $[9,10]$. To increase local prostate cancer control, the prescribed external beam radiation therapy dose has been increased from an average of 66 Gy in the mid-90s to between 72 and 81 Gy now especially with the use of intensity modulated radiation therapy and $3 \mathrm{D}$ conformal radiation therapy $[10,11]$. We have also determined the sensitivity of the $\alpha / \beta$ ratio for various values of the external radiation therapy dose from 66 Gy to 80 Gy.

Many authors have determined the $\alpha / \beta$ for prostate cancer and most analyses show that the $\alpha / \beta$ is lower than that determined for most other cancers [12-14]. Our determination of the $\alpha / \beta$ for prostate is built on the efforts made by other investigators. Our assessment takes into consideration the uncertainty in the dose delivered through PSI brachytherapy. It also takes into account the fact that the prescription dose for external beam therapy for prostate cancer has increased from about 66 Gy to $80 \mathrm{~Gy}$ in the past 20 years.

The relative biological effectiveness (RBE) of any biological system depends on the linear energy transfer of the ionizing radiation and multiplevariables determine RBE and that low energy photons generate higher LET electrons. Many studies have indicated that the relative biological effectiveness (RBE) dose for ${ }^{125} \mathrm{I}$ and ${ }^{103} \mathrm{Pd}$ are significantly different from unity ranging from 1.0 to over 2.0 for the dose rate used in permanent prostate implant brachytherapy with these isotopes $[15,16]$. We have incorporated various published value of the RBE in our determination of $\alpha / \beta$. Other studies by Nath et al. [17] suggest that the RBE could be significantly lower than unity if doserate effects are considered in the evaluation of RBE. We have also evaluated $\alpha / \beta$ for RBE values in the range of 0.8 to 2.0. The main purpose of our investigation was to determine a range of $\alpha / \beta$ ratio values for prostate cancer given that the total dose delivered with ${ }^{125} \mathrm{I}$ and ${ }^{103} \mathrm{Pd}$ PSI can vary considerably between patients treated in different cancer centers around the world.

\section{Materials and Methods}

Using published data documenting the errors associated with prostate radioactive seed implant brachytherapy, we have recalculated the $\alpha / \beta$ ratio for the prostate for a given equivalent external beam radiation dose. According to the linear quadratic model of cell killing by radiation, the survival fraction $\mathrm{SF}_{\mathrm{d}}$, of target cells after a dose per fraction $d$ is given by:

$$
\mathrm{SF}_{\mathrm{d}}=\exp \left(-\alpha \mathrm{d}-\beta \mathrm{d}^{2}\right)
$$

The effect, E, of delivering $\mathrm{n}$ such fractions can be expressed as:

$$
\begin{aligned}
& \mathrm{E}=-\log _{\mathrm{e}}\left(\mathrm{SF}_{\mathrm{d}}\right)^{\mathrm{n}}=-\log _{\mathrm{e}}\left(\mathrm{SF}_{\mathrm{d}}\right) \\
& \mathrm{E}=\mathrm{n}\left(\alpha \mathrm{d}+\beta \mathrm{d}^{2}\right)=\alpha \mathrm{D}+\beta \mathrm{dD}
\end{aligned}
$$

Where $D=n d$, the total physical dose delivered to the target (the dose per fraction $d$, multiplied by the number of fractions $n$ ). Equation 3 can be expressed in terms of the biological effective dose (BED)

$$
E / \alpha=n d\left[1+\frac{d}{\alpha / \beta}\right]
$$

Where $\mathrm{E} / \alpha$ is known as the biological effective dose (BED), $n d$ is the total dose (number of fractions $\mathrm{x}$ dose per fraction), and is known as the relative effectiveness of the radiation. The analysis shown in equations 1 to 4 is applicable for external beam radiation therapy.

For brachytherapy, the biological effective dose (BED) is given by [18]

$$
E / \alpha=T D_{\text {impalnt }}\left[R B E_{\max }+\frac{R 0}{\mu(\alpha / \beta)}\right]
$$

Where $\mathrm{TD}_{\text {implant }}$ is the total physical dose delivered following complete decay of the radionuclide, $\mathrm{RBE}_{\max }$ is the maximum Relative Biological Effectiveness for ${ }^{125} \mathrm{I} \gamma$-rays compared to ${ }^{60} \mathrm{Co} \gamma$-rays, $\mathrm{R}_{0}$ is the initial dose rate for the implant and $\mu$ is the repair constant for sublethal damage. Similarly, the biological effective dose (BED) for external beam radiation therapy is given by

$$
E / \alpha=T D_{e x t}\left[R B E_{\max }^{e x t}+\frac{d}{\mu(\alpha / \beta)}\right]
$$

Where TDext is the prescription dose for external radiation therapy and $d$ is the dose per fraction. For external beam radiotherapy with megavoltage photons, letting

Hence we obtain

$$
E / \alpha=T D_{e x t}\left[1+\frac{d}{(\alpha / \beta)}\right]=E / \alpha=n d\left[1+\frac{d}{(\alpha / \beta)}\right](7)
$$

We now equate the E/ $\alpha$ from equations 5 and 6 to obtain the $\alpha / \beta$ ratio as

$$
\alpha / \beta=\frac{d T D_{e_{X} t}-R_{0} T D_{\text {implant }}}{\left(T D_{\text {implant }} R E_{\max }-T D_{\text {ex }} t\right)}
$$

Using equation 8 , we can now determine the $\alpha / \beta$ ratio for various value of the external beam dose, implanted dose and RBE. In this analysis we have assumed that repair half life is 2 hours giving $\mu$ a value of 0.347 . The initial dose rate for ${ }^{125} \mathrm{I}$ is assumed to be 0.077 $\mathrm{Gy} / \mathrm{hr}$ while for the value for ${ }^{103} \mathrm{Pd}$ is assumed to be $0.20 \mathrm{~Gy} / \mathrm{hr}$. 
Citation: Mobit P, Agyingi E, Packianathan S, Yang CC (2015) What do Dosimetric Errors Encountered in Prostate Implant Brachytherapy tell us about $\alpha / \beta$ ?. J Nucl Med Radiat Ther 6: 214. doi:10.4172/2155-9619.1000214

Page 3 of 6

\section{Results}

\section{Dependence of the $\alpha / \beta$ on different RBE values}

Table 1 shows the $\alpha / \beta$ ratio for different values of implanted dose $\mathrm{Td}_{\text {implant }}$ and $\mathrm{RBE}$ values of $1.0,1.3$ and 2.0 for 125I. In the calculations, we have assumed an external beam radiotherapy dose of 74 Gy delivered in fractions of 2 Gy. We see clearly that the $\alpha / \beta$ ratio changes from 0.38 to 4.4 for an implanted 125I dose of $180 \mathrm{~Gy}$ and 100 Gy, respectively. We note that when $\mathrm{RBE}=1$, the $\alpha / \beta$ ratio varies between 1.02 and 4.4. If one were to use the most common PSI dose of $145 \mathrm{~Gy}$ for $125 \mathrm{I}$, then the $\alpha / \beta$ ratio would vary between 1.51 and 0.51 for RBE values of 1.0 and 2.0. So there is a significant dependence of $\alpha /$ $\beta$ on the RBE. By increasing the RBE value of $125 \mathrm{I}$ from 1 to 1.3 , there is a $28 \%$ reduction of the $\alpha / \beta$ ratio for a PSI dose of $145 \mathrm{~Gy}$.

\begin{tabular}{|c|c|c|c|}
\hline \multirow{2}{*}{$\begin{array}{l}T_{d_{\text {implant }}} \\
(G y)\end{array}$} & \multicolumn{3}{|c|}{$\alpha / \beta$ ratio for different values of $R B E$ for $1-125$ implant } \\
\hline & $\begin{array}{l}1.02 \text { Thios is } \\
\text { sample for the }\end{array}$ & $\begin{array}{l}1.02 \text { Thios is } \\
\text { sample for the }\end{array}$ & $\begin{array}{l}\text { 1.02 Thios is sample } \\
\text { for the }\end{array}$ \\
\hline 180 & 1.02 & 0.67 & 0.38 \\
\hline 170 & 1.15 & 0.75 & 0.41 \\
\hline 160 & 1.31 & 0.84 & 0.46 \\
\hline 145 & 1.51 & 0.95 & 0.51 \\
\hline 140 & 1.63 & 1.01 & 0.54 \\
\hline 135 & 1.77 & 1.08 & 0.57 \\
\hline 130 & 1.93 & 1.16 & 0.60 \\
\hline 125 & 2.13 & 1.25 & 0.64 \\
\hline 120 & 2.36 & 1.36 & 0.68 \\
\hline 115 & 2.64 & 1.48 & 0.73 \\
\hline 110 & 2.99 & 1.62 & 0.78 \\
\hline 109 & 3.43 & 1.79 & 0.85 \\
\hline 105 & 3.54 & 1.83 & 0.86 \\
\hline 102 & 4.02 & 1.99 & 0.92 \\
\hline 100 & 4.47 & 2.13 & 0.96 \\
\hline
\end{tabular}

Table 1: Dependence of the $\alpha / \beta$ ratio on different $R B E$ values using 125I. $\mathrm{TD}_{\mathrm{ext}}=74 \mathrm{~Gy}$ given in $2 \mathrm{~Gy}$ daily dose fractions.

\section{Dependence of the $\alpha / \beta$ on different external beam prescription doses}

As previously stated, the prescription dose for external beam radiation therapy can now vary between $72 \mathrm{~Gy}$ and $81 \mathrm{~Gy}$ so it is important to incorporate these new radiation prescription doses into our calculations. Tables 2 and 3 show the $\alpha / \beta$ ratios for external beam doses for ${ }^{125} \mathrm{I}$ for RBE values of 1 and 2 , respectively. The $\alpha / \beta$ ratio varies between 0.96 and 6.1 for RBE of 1.0 and between 0.64 and 2.6 for an RBE of 2.0. It is important to note that as the value of the external beam radiation dose prescription increases from 72 to $80 \mathrm{~Gy}$, the $\alpha / \beta$ value increases by an average of $16 \%$.
Table 4 shows the calculated $\alpha / \beta$ ratio for different values of PSI dose ( $\mathrm{Td}^{\mathrm{Pd}-103}$ impant) and different $\mathrm{RBE}$ values utilizing ${ }^{103} \mathrm{Pd}$ radioactive sources. The $\alpha / \beta$ ratio varies from 0.27 to 6.01 for a PSI dose that varies between 90 and $150 \mathrm{~Gy}$ for ${ }^{103} \mathrm{Pd}$. When the RBE is assumed to be 1 , the $\alpha / \beta$ ratio varies between 0.81 and 6.01 . If one were to use the most common PSI dose for ${ }^{103} \mathrm{Pd}$ of $124 \mathrm{~Gy}$, then the $\alpha / \beta$ ratio would vary between 0.44 and 1.53 , for RBE values between 1.0 and 2.0.

\begin{tabular}{|c|c|c|c|c|}
\hline \multirow[t]{2}{*}{$\begin{array}{l}T_{\text {implant }} \\
(G y)\end{array}$} & \multicolumn{4}{|c|}{$\begin{array}{l}\alpha / \beta \text { ratio for different values of equivalent external beam } \\
\text { dose }\end{array}$} \\
\hline & $72.0 \mathrm{~Gy}$ & 74.0 & 78.0 & $80.0 \mathrm{~Gy}$ \\
\hline 180 & 0.96 & 1.02 & 1.08 & 1.14 \\
\hline 170 & 1.08 & 1.15 & 1.21 & 1.28 \\
\hline 160 & 1.23 & 1.31 & 1.39 & 1.47 \\
\hline 150 & 1.42 & 1.51 & 1.60 & 1.70 \\
\hline 145 & 1.53 & 1.63 & 1.74 & 1.85 \\
\hline 140 & 1.66 & 1.77 & 1.89 & 2.01 \\
\hline 135 & 1.81 & 1.93 & 2.07 & 2.21 \\
\hline 130 & 1.98 & 2.12 & 2.28 & 2.44 \\
\hline 125 & 2.19 & 2.35 & 2.53 & 2.73 \\
\hline 120 & 2.44 & 2.63 & 2.85 & 3.08 \\
\hline 115 & 2.75 & 2.98 & 3.24 & 3.53 \\
\hline 110 & 3.14 & 3.42 & 3.75 & 4.11 \\
\hline 105 & 3.66 & 4.00 & 4.44 & 4.91 \\
\hline 100 & 4.35 & 4.81 & 5.41 & 6.08 \\
\hline
\end{tabular}

Table 2: Variation of $\alpha / \beta$ ratio and the total implant dose $\mathrm{Td}_{\text {impant }}$ with value of the external photon beam dose for ${ }^{125} \mathrm{I}$ (RBE value of 1.0).

\begin{tabular}{|c|c|c|c|c|}
\hline \multirow[t]{2}{*}{$\mathbf{T d}_{\text {implant }}(\mathbf{G y})$} & \multicolumn{4}{|c|}{$\begin{array}{l}\alpha / \beta \text { ratio for different value of equivalent external beam } \\
\text { dose }\end{array}$} \\
\hline & 72 Gy & $74 \mathrm{~Gy}$ & $78 \mathrm{~Gy}$ & $80 \mathrm{~Gy}$ \\
\hline 180 & 0.64 & 0.67 & 0.71 & 0.74 \\
\hline 170 & 0.71 & 0.75 & 0.79 & 0.83 \\
\hline 160 & 0.80 & 0.84 & 0.88 & 0.93 \\
\hline 150 & 0.90 & 0.95 & 1.00 & 1.05 \\
\hline 145 & 0.96 & 1.01 & 1.06 & 1.12 \\
\hline 140 & 1.03 & 1.08 & 1.14 & 1.20 \\
\hline 135 & 1.10 & 1.16 & 1.23 & 1.29 \\
\hline 130 & 1.19 & 1.25 & 1.32 & 1.40 \\
\hline 125 & 1.28 & 1.36 & 1.44 & 1.52 \\
\hline 120 & 1.40 & 1.48 & 1.57 & 1.66 \\
\hline 115 & 1.53 & 1.62 & 1.72 & 1.82 \\
\hline
\end{tabular}


Citation: Mobit P, Agyingi E, Packianathan S, Yang CC (2015) What do Dosimetric Errors Encountered in Prostate Implant Brachytherapy tell us about $\alpha / \beta$ ?. J Nucl Med Radiat Ther 6: 214. doi:10.4172/2155-9619.1000214

Page 4 of 6

\begin{tabular}{|l|l|l|l|l|}
\hline 110 & 1.68 & 1.79 & 1.90 & 2.02 \\
\hline 105 & 1.87 & 1.99 & 2.13 & 2.27 \\
\hline 100 & 2.10 & 2.24 & 2.40 & 2.57 \\
\hline
\end{tabular}

Table 3: Variation of $\alpha / \beta$ ratio and the total implant dose $\mathrm{Td}_{\text {implant }}$ with value of the external photon beam dose for ${ }^{125} \mathrm{I}$ (RBE value of 2.0).

\begin{tabular}{|c|c|c|c|}
\hline \multirow{2}{*}{$\mathbf{T d}_{\text {implant }}(\mathbf{G y})$} & \multicolumn{3}{|c|}{$\boldsymbol{\alpha} / \boldsymbol{\beta}$ ratio for different values of RBE for Pd-103 implant } \\
\cline { 2 - 4 } & $\begin{array}{c}1.02 \text { Thios is } \\
\text { sample for the }\end{array}$ & $\begin{array}{c}1.02 \text { Thios is } \\
\text { sample for the }\end{array}$ & $\begin{array}{c}1.02 \text { Thios is } \\
\text { sample for the }\end{array}$ \\
\hline 150.0 & 0.81 & 0.41 & 0.27 \\
\hline 145.0 & 0.91 & 0.45 & 0.30 \\
\hline 140.0 & 1.02 & 0.49 & 0.33 \\
\hline 135.0 & 1.15 & 0.55 & 0.36 \\
\hline 130.0 & 1.30 & 0.60 & 0.39 \\
\hline 124.0 & 1.53 & 0.68 & 0.44 \\
\hline 119.0 & 1.76 & 0.76 & 0.48 \\
\hline 114.0 & 2.06 & 0.85 & 0.53 \\
\hline 110.0 & 2.35 & 0.93 & 0.58 \\
\hline 109.0 & 2.43 & 0.95 & 0.59 \\
\hline 105.0 & 2.82 & 1.05 & 0.64 \\
\hline 102.0 & 3.19 & 1.13 & 0.69 \\
\hline 100.0 & 3.48 & 1.19 & 0.72 \\
\hline 90.0 & 6.01 & 1.58 & 0.91 \\
\hline & & & \\
\hline & & & 0.95 \\
\hline
\end{tabular}

Table 4: Dependence of the $\alpha / \beta$ ratio on different values of RBE using ${ }^{103} \mathrm{Pd}$. $\mathrm{TD}_{\text {ext }}=74 \mathrm{~Gy}$ given in $2 \mathrm{~Gy}$ daily dose fractions.

Tables 5 and 6 show the $\alpha / \beta$ ratio calculated for ${ }^{103} \mathrm{Pd}$ prostate implant brachytherapy doses and different values of the external beam doses. Table 5 shows data for RBE of 1.0 and Table 6 shows the data for $\mathrm{RBE}$ of 2.0. We note that for the RBE of 1 , the $\alpha / \beta$ ratio varies between 0.74 and 10.81. Again if one assumes the most realistic value of the PSI dose for ${ }^{103} \mathrm{Pd}$ of $124 \mathrm{~Gy}$, then $\alpha / \beta$ would vary between 1.4 and 2.01 .

\begin{tabular}{|c|c|c|c|c|c|}
\hline \multirow{2}{*}{$\operatorname{Td}_{\text {implant }}(\mathbf{G y})$} & \multicolumn{6}{|c|}{$\begin{array}{l}\boldsymbol{\alpha} / \boldsymbol{\beta} \text { ratio for different value of equivalent external beam } \\
\text { dose }\end{array}$} \\
\cline { 2 - 6 } & $\mathbf{7 2} \mathbf{~ G y}$ & $\mathbf{7 4} \mathbf{~ G y}$ & $\mathbf{7 6} \mathbf{~ y}$ & $\mathbf{7 8 ~ G y}$ & $\mathbf{8 0 ~ G y}$ \\
\hline 150.0 & 0.74 & 0.79 & 0.89 & 0.97 & 1.05 \\
\hline 145.0 & 0.83 & 0.90 & 0.99 & 1.08 & 1.18 \\
\hline 140.0 & 0.93 & 1.02 & 1.11 & 1.21 & 1.32 \\
\hline 135.0 & 1.05 & 1.16 & 1.26 & 1.37 & 1.49 \\
\hline 130.0 & 1.19 & 1.33 & 1.43 & 1.56 & 1.70 \\
\hline 124.0 & 1.39 & 1.58 & 1.68 & 1.84 & 2.01 \\
\hline
\end{tabular}

\begin{tabular}{|l|l|l|l|l|l|}
\hline 120.0 & 1.56 & 1.79 & 1.88 & 2.07 & 2.27 \\
\hline 115.0 & 1.81 & 2.11 & 2.20 & 2.42 & 2.68 \\
\hline 110.0 & 2.12 & 2.53 & 2.61 & 2.89 & 3.22 \\
\hline 105.0 & 2.53 & 3.11 & 3.15 & 3.54 & 3.98 \\
\hline 100.0 & 3.08 & 3.95 & 3.93 & 4.47 & 5.12 \\
\hline 90.0 & 5.12 & 7.69 & 7.15 & 8.68 & 10.81 \\
\hline
\end{tabular}

Table 5: Variation of $\alpha / \beta$ ratio and the total implant dose $\operatorname{Td}_{\text {implant }}$ with value of the external photon beam dose for ${ }^{103} \mathrm{Pd}$ for $\mathrm{RBE}=1.0$.

\begin{tabular}{|c|c|c|c|c|c|}
\hline \multirow[t]{2}{*}{$\mathbf{T d}_{\text {implant }}$ (Gy) } & \multicolumn{5}{|c|}{$\begin{array}{l}\alpha / \beta \text { ratio for different value of equivalent external beam } \\
\text { dose }\end{array}$} \\
\hline & $72 \mathrm{~Gy}$ & 74 Gy & $76 \mathrm{~Gy}$ & $78 \mathrm{~Gy}$ & $80 \mathrm{~Gy}$ \\
\hline 150.0 & 0.38 & 0.39 & 0.44 & 0.47 & 0.51 \\
\hline 145.0 & 0.42 & 0.43 & 0.48 & 0.52 & 0.56 \\
\hline 140.0 & 0.46 & 0.48 & 0.53 & 0.57 & 0.61 \\
\hline 135.0 & 0.51 & 0.53 & 0.59 & 0.63 & 0.67 \\
\hline 130.0 & 0.56 & 0.59 & 0.65 & 0.69 & 0.74 \\
\hline 124.0 & 0.64 & 0.67 & 0.73 & 0.78 & 0.84 \\
\hline 120.0 & 0.69 & 0.74 & 0.80 & 0.85 & 0.91 \\
\hline 115.0 & 0.77 & 0.83 & 0.89 & 0.95 & 1.01 \\
\hline 110.0 & 0.87 & 0.93 & 1.00 & 1.06 & 1.14 \\
\hline 105.0 & 0.98 & 1.06 & 1.12 & 1.20 & 1.28 \\
\hline 100.0 & 1.11 & 1.21 & 1.28 & 1.37 & 1.46 \\
\hline 90.0 & 1.46 & 1.64 & 1.70 & 1.83 & 1.97 \\
\hline
\end{tabular}

Table 6: Variation of $\alpha / \beta$ ratio and the total implant dose $\operatorname{Td}_{\text {implant }}$ with value of the external photon beam dose for ${ }^{103} \mathrm{Pd}$ for $\mathrm{RBE}=2.0$.

\section{Discussion}

The linear quadratic model in radiation oncology attempts to describe the degree of curvature of a cell survival curve. The $\alpha / \beta$ ratio is the radiation dose where cell killing due to the linear and quadratic components of the equation are equal. Generally, rapidly dividing cancer cells are associated with higher values of the $\alpha / \beta$ ratio compared to slow growing cells. A value of 10 is the normally attributed as the $\alpha /$ $\beta$ ratio for most tumors while a value of 3 is often assumed for normal tissue or cells. Prostate cancer is in fact different from most cancers in that the tumor progression is typically slow. Organs at risks or normal tissue surrounding the tumor may have a higher value of $\alpha / \beta$ ratio than the prostate itself. Our calculations which are based on using the current treatment prescription dose for prostate cancer with both external beam and prostate implant brachytherapy points to lower $\alpha / \beta$ ratio for prostate.

Stock et al. [19] demonstrated a dose response relationship correlating $\mathrm{D}_{90}$ with probability of biochemical control and showed that a $\mathrm{D}_{90}$ greater than $140 \mathrm{~Gy}$ is a highly significant factor in predicting PSA relapse free survival (PSA-RFS). Ash et al. [9] on the 
Citation: Mobit P, Agyingi E, Packianathan S, Yang CC (2015) What do Dosimetric Errors Encountered in Prostate Implant Brachytherapy tell us about $\alpha / \beta$ ?. J Nucl Med Radiat Ther 6: 214. doi:10.4172/2155-9619.1000214

Page 5 of 6

other hand demonstrated no correlation between value of $\mathrm{D}_{90}$ and outcome for their patient population of 667 . Their data showed that $20 \%$ of their patients had $\mathrm{D}_{90}$ less than $120 \mathrm{~Gy}$. Since $\mathrm{D}_{90}$ represents the dose delivered to $90 \%$ of the prostate volume, it means that at least $20 \%$ of their prostate cancer patients received doses less than $120 \mathrm{~Gy}$. Despite these lower doses, these patients did not perform any worse than the other patients who had a higher $\mathrm{D}_{90}$. The implication for this may be that the RBE value for ${ }^{125} \mathrm{I}$ and ${ }^{103} \mathrm{Pd}$ is considerably greater than unity so that a lower delivered dose to the patient is still sufficient to control their cancer. A higher value of RBE is associated with a lower value of the $\alpha / \beta$ as demonstrated in Tables 1 and 2 and also 4 and 6. It is also interesting to note that Nath [17] demonstrated that the higher value of the RBE for low energy brachytherapy sources like ${ }^{103} \mathrm{Pd}$ and ${ }^{125} \mathrm{I}$ would be completely negated when dose rate effects are taken into account.

Another consideration in the determination of the $\alpha / \beta$ for prostate implant brachytherapy is that the initial dose rate for ${ }^{125} \mathrm{I}$ is assumed in these calculations to be $0.08 \mathrm{~Gy} / \mathrm{hr}$ and this means that the effective treatment time is 122 days as suggested by Wang et al. [20]. This suggests that only $75 \%$ of the prescription dose for ${ }^{125} \mathrm{I}$ is delivered and the rest of the dose is wasted as the dose rate by then is so low that in any cell killing by the radiation is balanced by repopulation. This points to a higher value of the $\alpha / \beta$ ratio for prostate cancer. If one were to combine these findings with the physical uncertainty caused by seed migration, then physical doses delivered to the prostate gland for brachytherapy procedure would be much less than the prescribed dose of $125 \mathrm{~Gy}$ or $145 \mathrm{~Gy}$ with ${ }^{103} \mathrm{Pd}$ and ${ }^{125} \mathrm{I}$ respectively. Thus the realistic values of the $\alpha / \beta$ ratio for prostate may be higher than 1.5 and unlikely to be below 1.0.

There is little doubt that the $\alpha / \beta$ ratio may vary between patients and may also vary within the prostate volume of the same patient. Previous determinations of the $\alpha / \beta$ ratio for ${ }^{125} \mathrm{I}$ and ${ }^{103} \mathrm{Pd}$ have assumed that the dose delivered during permanent seed implant brachytherapy treatment for prostate cancer is well defined at $145 \mathrm{~Gy}$ and $125 \mathrm{~Gy}$, respectively and the external beam dose is defined at 72 Gy or greater. In reality, however, the patient may receive a range of doses in such implant brachytherapy depending on the quality of the implant and the rigor of the planning objectives. Even though a postimplant CT is typically performed a month after the implant to assess its quality, it is not always possible to determine exactly the orientation of the seeds and the seeds may also have migrated from their original implant positions. Even if the seeds were to be identified, they are taken to be point sources with no information about the actual orientation of individual radioactive sources. It is important to note that the systematic errors associated with prostate seeds implant brachytherapy are not common with 3D- or IMRT-based external beam radiation therapy treatments; thus, one may assume that prostate would have received the full prescription dose in those instances. The effect of tumor repopulation has not been taken into account but it is thought to be negligible for the low-dose-rate permanent implants.

\section{Conclusion}

Despite the uncertainties in the calculation of the alpha beta ratio for prostate cancer, our analyses suggest that the $\alpha / \beta$ ratio could be as low as 0.5 . It is important to note that calculation of the $\alpha / \beta$ ratio must also incorporate dosimetric uncertainties associated with permanent prostate seed implant brachytherapy and the fact that different external beam radiation doses have been used. Increasing the RBE of low energy permanent brachytherapy sources like ${ }^{125} \mathrm{I}$ and ${ }^{103} \mathrm{Pd}$ leads to a lower value of the $\alpha / \beta$ ratio for prostate.

\section{Conflict of Interest}

All authors certify that this manuscript has not been published in whole or in part nor is it being considered for publication elsewhere. The authors indicate no disclosure of potential conflicts of interest.

\section{References}

1. Bowes D, Crook J (2011) A critical analysis of the long-term impact of brachytherapy for prostate cancer: a review of the recent literature. Curr Opin Urol 21: 219-224.

2. Nag S, Beyer D, Friedland J, Grimm P, Nath R (1999) American Brachytherapy Society (ABS) recommendations for transperineal permanent brachytherapy of prostate cancer. Int J Radiat Oncol Biol Phys 44: 789-799.

3. Yu Y, Waterman FM, Suntharalingam N, Schulsinger A (1996) Limitations of the minimum peripheral dose as a parameter for dose specification in permanent $125 \mathrm{I}$ prostate implants. Int J Radiat Oncol Biol Phys 34: 717-725.

4. Nath S, Chen Z, Yue N, Trumpore S, Peschel R (2000) Dosimetric effects of needle divergence in prostate seed implant using 125I and 103Pd radioactive seeds. Med Phys 27: 1058-1066.

5. Butler WM, Merrick GS, Dorsey AT, Lief JH (2000) Isotope choice and the effect of edema on prostate brachytherapy dosimetry. Med Phys 27: 1067-1075.

6. Lee WR, Roach III M, Michalski J, Moran B, Bever D (2002) Interobserver variability leads to significant differences in quantifiers of prostate implant adequacy. Int. J. Radiat. Oncol. Biol. Phys 54: 457-461.

7. Lindsay PE, Van Dyk J, Battista JJ (2003) A systematic study of imaging uncertainties and their impact on 125I prostate brachytherapy dose evaluation. Med Phys 30: 1897-1908.

8. Nath R, Bice WS, Butler WM, Chen Z, Meigooni AS, et al. (2009) AAPM recommendations on dose prescription and reporting methods for permanent interstitial brachytherapy for prostate cancer: Report of Task Group 137. Med Phys. 36: 5310-5322.

9. Ash D, Al-Qaisieh B, Bottomley D, Carey B, Joseph J (2006) The correlation between D90 and outcome for I-125 seed implant monotherapy for localised prostate cancer. Radiother Oncol 79: 185-189.

10. Goldner G, Dimopoulos J, Kirisits C, Pötter R (2009) Moderate Dose Escalation in Three-Dimensional Conformal Localized Prostate Cancer Radiotherapy Single-Institutional Experience in 398 Patients Comparing 66 Gy versus 70 Gy versus 74 Gy. Strahlenther. Onkol 185: 438-445.

11. Brabbins D, Martinez A, Yan D, Lockman D, Wallace M, et al.(2005) A dose-escalation trial with the adaptive radiotherapy process as a delivery system in localized prostate cancer: Analysis of chronic toxicity. Int J. Radiat. Oncol. Biol. Phys 61: 400-408.

12. Brenner DJ, Martinez AA, Edmundson GK, Mitchell C, Thames HD, et al. (2002) Direct evidence that prostate tumors show high sensitivity to fractionation (low alpha/beta ratio), similar to late-responding normal tissue. Int J Radiat Oncol Biol Phys 52: 6-13.

13. Williams SG, Taylor JM, Liu N, Tra Y, Duchesne GM, et al. (2007) Use of individual fraction size data from 3756 patients to directly determine the alpha/beta ratio of prostate cancer. Int J Radiat Oncol Biol Phys 68: 24-33.

14. Duchesne GM, Peters LJ (1999) What is the alpha/beta ratio for prostate cancer? Rationale for hypofractionated high-dose-rate brachytherapy. Int J Radiat Oncol Biol Phys 44: 747-748.

15. Wuu CS, Kliauga P, Zaider M, Amols HI (1996) Microdosimetric evaluation of relative biological effectiveness for 103Pd, 125I, 241 Am, and 192Ir brachytherapy sources. Int J Radiat Oncol Biol Phys 36: 689-697. 
Citation: Mobit P, Agyingi E, Packianathan S, Yang CC (2015) What do Dosimetric Errors Encountered in Prostate Implant Brachytherapy tell us about $\alpha / \beta$ ?. J Nucl Med Radiat Ther 6: 214. doi:10.4172/2155-9619.1000214

Page 6 of 6

16. Ling CC, Li WX, Anderson LL (1995) The relative biological effectiveness of I-125 and Pd-103. Int J Radiat Oncol Biol Phys 32: 373-378.

17. Nath R, Bongiorni P, Chen Z, Gragnano J, Rockwell S (2005) Dose rate dependence of the relative biological effectiveness of 103Pd for continuous low dose rate irradiation of BA1112 rhabdomyosarcoma cells in vitro relative to acute exposures. Int J Radiat Biol 81: 689-699.

18. Fowler J, Chappell R, Ritter M (2001) Is alpha/beta for prostate tumors really low? Int J Radiat Oncol Biol Phys 50: 1021-1031.
19. Stock RG, Stone NN, Tabert A, Iannuzzi C, DeWyngaert JK (1998) A dose-response study for I-125 prostate implants. Int J Radiat Oncol Biol Phys 41: 101-108.

20. Wang JZ, Li XA, Yu CX, DiBiase SJ (2003) The low alpha/beta ratio for prostate cancer: what does the clinical outcome of HDR brachytherapy tell us? Int J Radiat Oncol Biol Phys 57: 1101-1108. 